\title{
'Centering' Teaching Excellence in Higher Education
}

\section{Diarmaid Lane}

School of Education, University of Limerick, Ireland.

\begin{abstract}
This paper explores the complexity of 'teaching excellence' (Kreber, 2002) in contemporary higher education. It describes how a university academic, who has been the recipient of numerous teaching awards, questions if they really are an 'excellent teacher' and if their student-centered philosophy is sustainable. An analysis of data related to teaching and learning effectiveness over a seven year period highlights a significant weakness in how the academic approached the teaching of undergraduate students. This had a subsequent negative effect on several levels. The paper concludes by describing the merits of academics 'centering' themselves between the corporate university and the needs of students in striving for 'teaching excellence'.
\end{abstract}

Keywords: teaching; learning; university; excellence; corporatization; philosophy. 


\section{Introduction}

Historically, university academics were afforded time and space to shape their research and scholarship endeavors (Berg \& Seeber, 2016). In modern times, universities are competing in a fast-paced global market (Altbach, 2007) in which governance by numbers (Ball, 2015) and outcomes-based educational accountability (Beauchamp et al., 2016) dominate. The 'corporatization of the contemporary university' (Berg \& Seeber, 2016) means that almost all facets of operating a successful and competitive institution are now quantifiable. Academics are increasingly expected to attend to the governance of their own institutions by ensuring that the inner core of the corporate shell upholds traditional values around learning, scholarship, and service (Steck, 2003). This paper examines the following research question; how effective and sustainable is a student-centered teaching philosophy when teaching large class groups within a research intensive university?

\subsection{Teacher and Mentor}

On commencing my tenure as a junior academic, I had a very utopian view of how I wanted to approach my teaching. At the time, I was teaching between 240-260 undergraduate students per semester. I considered myself as both a teacher and a mentor. I enjoyed the 'distinctive pleasures’ (Berg \& Seeber, 2016, p. 34) of teaching and learning. I believed that all students deserved support and time, especially during their first year of study. The experience of students and their success was my priority. Everything else including my research took second place. Refining and improving my pedagogical approach and assessment mechanisms became part of my daily work, constantly striving to make the learning experience of the students more meaningful, stimulating and rewarding. I wanted all students to understand the content and concepts that I taught, and I used a range of different strategies to ensure that everybody received the support they required.

My teaching evaluations were outstanding, scoring consistently high on all scales. I received numerous awards for 'Excellence in Teaching' at both a local and regional level and I was extended special invites to present my teaching philosophy and related approaches to other academics and teachers. Interestingly, I often delivered modules where the evaluation scores for my teaching were very high, yet a high percentage of students often failed. I found this puzzling - if students found the module and the associated teaching to be so effective, why were so many students failing? Approximately two years ago, I was forced to think critically about this when my Head of School raised concerns about the percentage of students not progressing to Year 2 of their respective program of study. From a management perspective the 'numbers' associated with this were unsatisfactory as it had a knock-on effect on performance metrics, degree awards and scheduling, among other things. In an attempt to explain how I critically examined my teaching philosophy, the next section of the paper focuses on empirical data related to my teaching and the performance of students. 


\section{Method}

Measuring and examining 'teaching quality' through the lens of a teaching philosophy is complex. This could be due to the ambiguity regarding the interpretation of 'effective teaching' (Kreber, 2002; Perrott, 1982). Universities are increasingly using performance indicators (PIs) (Ramsden, 1991) to quantitatively measure performance of students and academics. In order to self-examine the effectiveness of my teaching I examined a Year 1, Semester 2 'Design and Communication Graphics 1' (DCG) module on an Initial Technology Teacher Education program over a seven-year period from 2012-2018. I was the sole leader of this module over that period. This core module has historically been cited as a 'difficult module' and a predictor of overall degree award at the end of a four-year program. The module aims to develop student teachers foundation knowledge and skills in the area of DCG to equip them to effectively teach the subject in secondary schools on graduation from university. The module is completed over a 15 week period and includes an extensive coursework element that is formatively assessed in addition to a midterm and end of term examination. Over 100 students are enrolled on the module each year. The following are the variables that were analyzed:

- Overall Percentage of Fail Grades: Deficient grades are undesirable for both the student and the university. Students cannot progress to the next year of their study unless this grade is cleared through a repeat mechanism. Deficient grades have a negative impact on the level of degree award obtained by the student at the end of their degree program and they also put strains on university resources and scheduling. These data were analyzed on completion of the module each year.

- Overall Module Quality Credit Average (QCA): This weighted score describes the quality of performance in a module ranging from 0.00 (minimum) to 4.00 (maximum). These data were analyzed on completion of the module each year.

- Overall Teaching Effectiveness Score: This score is based on evaluations of teaching by the students taking the module. The online evaluations are independently administered by the Centre for Teaching and Learning at the university on Week 10 of each semester. All responses are anonymous. The ratings range from 0 (not effective) to 5 (extremely effective).

- Student Comments: A range of different qualitative comments from students in the teaching evaluations are examined.

Interested readers should note that participants in this study were from one particular course on an initial teacher education program and that other performance indicators (PIs) such as; peer ratings of teaching, wastage and completion rates (Ramsden, 1991) were not used. 


\section{Findings}

The data yielded over the time period from 2012-2018 are shown in Table 1. For each of the seven years, the class group size was greater than 100 students. The year that yielded the lowest QCA for the module was 2015. In that same year I was awarded a regional Teaching Award for Excellence in Teaching. This prestigious award is presented by a consortium of three higher education institutions in the local region as part of a shared mission to enhance the quality of teaching and learning. This is my most significant teaching award so far in my career. The highest overall percentage of Fail grades awarded in the module was in 2013 (25.9\%) and 2016 (25.6\%). In both of these years I was the recipient of local awards for excellence in teaching. This 'excellence in teaching' is supported in the consistently high Teaching Effectiveness scores in each year ${ }^{1}$.

Table 1. Variables associated with teaching and learning 2012-2018.

\begin{tabular}{cccccccc}
\hline Variable & $\mathbf{2 0 1 2}$ & $\mathbf{2 0 1 3}$ & $\mathbf{2 0 1 4}$ & $\mathbf{2 0 1 5}$ & $\mathbf{2 0 1 6}$ & $\mathbf{2 0 1 7}$ & $\mathbf{2 0 1 8}$ \\
\hline $\mathrm{N}$ & 124 & 135 & 111 & 127 & 121 & 107 & 105 \\
Overall \% of Fails Grades & $12.1 \%$ & $25.9 \%$ & $23.4 \%$ & $11.8 \%$ & $25.6 \%$ & $15 \%$ & $7.6 \%$ \\
Overall QCA & 2.51 & 2.18 & 2.42 & 2.08 & 2.2 & 2.59 & 2.79 \\
$\begin{array}{c}\text { Overall Teaching Effectiveness } \\
\text { Score }\end{array}$ & $4.8 / 5$ & $4.7 / 5$ & $4.7 / 5$ & $4.6 / 5$ & N/A1 & $4.68 / 5$ & N/A1 \\
& & & & & & &
\end{tabular}

Some qualitative comments that support my student-centered, supportive philosophy in the module are evident below:

- 'Cannot praise [name omitted] enough. He is an absolutely excellent lecturer and there is a consensus about this throughout the entire course. He is very helpful when you ask him a question no matter how simple it may be compared to other lecturers and T.A.'s'

- 'Very approachable and helpful lecturer. Difficult course content delivered very effectively and in an easily understood manner'

- 'This lecturer is very good and breaking difficult material into simple parts'

- 'Lecturer knows his subject area very well and passes on the information clearly'

- '[Name omitted] is almost the perfect person to teach this module, he clearly knows his stuff and is pretty good when it comes to explaining things'

\footnotetext{
${ }^{1}$ The formal Student Evaluation of Teaching was not offered by the university in 2016 and 2018.
} 
- ' [Name omitted] is an excellent module leader. He goes through everything in detail and makes it very easy to understand'

The selection of comments align with both my philosophy and the consistently high ratings for teaching effectiveness. Once again, this raised a concern - the students were very happy with their experience in the module yet, the performance of the students in assessments was relatively poor especially from 2013-2016. The data in Table 1 show that a marked improvement occurred in 2017 and the best 'numbers' for the module were in 2018.

\subsection{Critically examining the problem}

After numerous discussions with my Head of School, I agreed to investigate the root cause(s) of the consistent underperformance of Year 1 students in the module. After careful review of student demographics; subjects previously studied, grades on matriculation from secondary school, and semester workload across other modules, several conclusions were made. The academic abilities of students varied. This mixed ability was particularly evident in students' grades on matriculation from secondary school. Some were high achieving students who could easily have opted to study courses that would have demanded higher entry levels of academic achievement. Several students came from low socio-economic backgrounds or had learning disabilities, for which special provision was made to accommodate their entry on to the program if they didn't meet the minimum academic grade required for entry. This was typically a $65 \%$ grade average. I also examined workload across the other four modules that students study in the semester and found evidence that there was potentially a lack of coherency across modules and that students were overloaded in terms of contact hours, assignments, and exams.

I still couldn't ignore the fact that my teaching was considered excellent by students and the university, yet this anomaly of student underperformance persisted. I had a eureka moment in the spring of 2017; I realized that I was over-supporting the students.

\subsection{The Root Cause}

The program in which the module resides has been accredited since 2015 by the national council that governs the registration of teachers. The program was designed based on a model that reduced the contact time that students have with staff as they progress through the fouryear duration of the program. My teaching philosophy aligned perfectly with this model as it afforded me the time to spend with first-year students in the lectures and labs. It afforded me the time to design all sorts of learning aids and scaffolds to help students develop the skills and understanding that would equip them to become 'excellent' teachers. 


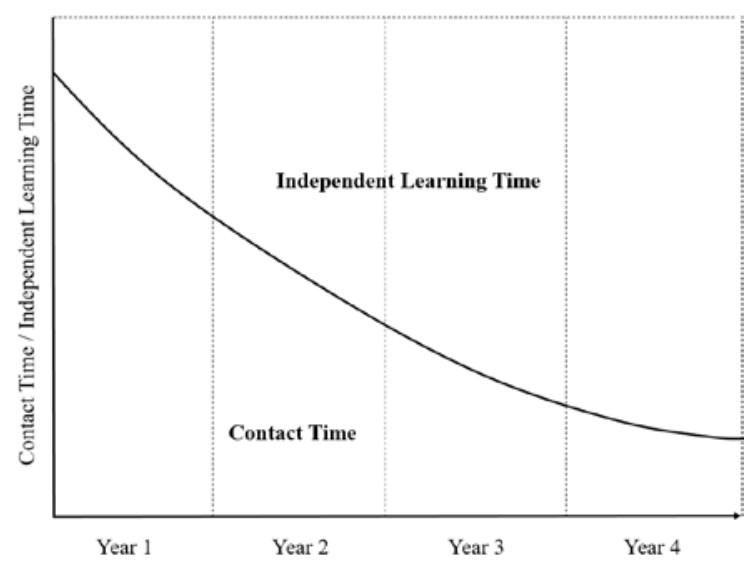

Figure 1. Contact time versus independent learning time

While the assessment of the module consistently indicated to me that there was something wrong, I didn't want to accept that it was due to student backgrounds or ability. I broke new ground when I examined the teaching evaluations for Year 3 modules I was delivering during the same period. According to the design and underpinning philosophy of the model (Figure 1), the Year 3 modules had significantly less contact time between teachers and the students. Many students were not comfortable with this and that was evident in the teaching evaluations where the effectiveness of my teaching dropped to 3.98 / 5.0 in 2017. While still a 'good' score, the mixed nature of the following comments highlights the root cause of the problem:

- 'We are not really being taught. We are expected to teach ourselves which is difficult to do.'

- $\quad$ Content needs to be covered more extensively in lectures and labs as it is very difficult for us to participate in collaborative work if there is a gap in our knowledge.'

- $\quad$ 'This module is very different to other modules that [Name omitted] has had with us. We aren't really covering content like we would have done in $1^{\text {st }}$ or $2^{\text {nd }}$ year.'

- ' 'Module is ran very well, hours cut down but that is for our benefit.'

- 'The self-learning and everything is great but if people don't put the work in the whole thing won't work.'

At this moment I realized that I probably over-supported these same students during their first year of study and that when the scaffold was reduced or removed the students struggled to learn independently and collaboratively. Therefore, it is not surprising that students struggled when I was not by their side when they completed their exam in Year 1. It is also 
not surprising that students' expressed dissatisfaction when my time with them was reduced as they progressed through the four years.

\section{Discussion}

My university prides itself on the attributes of its graduates; knowledgeable, proactive, creative, responsible, collaborative and articulate. In hindsight, I don't believe that the contact time versus independent time model presented in Figure 1 is appropriate as it arguably over-supports students with the significant amount of time that they are in contact with teaching staff during their first year of study. While this aligned with my teaching philosophy at the time, I now believe that this is potentially detrimental to students as their experience in secondary school is now arguably extended to third level and the supportive learning environment becomes normalized. Once established, it is very difficult to reduce or remove this scaffold as is evident in some of the comments received in Year 3 evaluations.

The overall class QCA in both 2017 and 2018 was the highest over the 2012-2018 period. What happened? In the spring of 2017, I decided to give students more responsibility for their learning when they commenced their studies. I assigned them weekly readings, experimented with 'flipping' lessons, and increased the amount of formative assessments. As a result, the overall QCA for the module has increased, the percentage of Fail grades has decreased, and the students ratings of teaching effectiveness remain high (4.68/5.0 in 2017, Table 1). While student comments remained generally positive, the following comment suggested that some students would still prefer to have a scaffolded experience such as the one they may have had in secondary school.

\section{'I feel that there are too many self-directed hours. I believe greater understanding of course material could be attained if more lecture/lab classes were undertaken with the instructor present.'}

\section{Year 1 Student 2017}

This raises the question; does such a student really need scaffolded academic support, do they lack confidence or are they lacking motivation? This is my current focus where I am investigating the merits of identifying at-risk students in the early weeks of Year 1 and providing these with special support while at the same time 'flipping' more of the learning for the more 'able' students and reducing the contact time.

\section{Conclusion}

I believe that this critical examination of my teaching has been worthwhile on several fronts. The university is now satisfied that students are performing better and that there are significantly fewer students failing. This has a direct positive impact on 'numbers'. Flipping 
classes and reducing contact time means that the costs associated with teaching are reduced. The students are largely happy based on the evaluations of teaching and the improved overall performance means that students now have a better chance of graduating with a higher degree award. I believe that this process has helped to 'center' me in a professional sense. Reducing the time I spend with students in first year means that I now have more time to engage in my scholarship activities. My teaching philosophy and passion for supporting and mentoring students remains intact - I am merely providing a structure now that facilitates students in becoming responsible, proactive and collaborative. Lunenberg et al. (2014) describe how teacher educators who function at a high professional level will have a positive impact on the quality of student teachers and on the future quality of the education system. Through the recent refinement of my teaching philosophy and associated practices described in this paper, I believe that my teaching will not only become more effective but it will also become more enjoyable on a petsonal level, and as a result it might help combat the negative effects of the current academic climate that often forces academics into states of stress and frustration with the larger system. This paper should help to stimulate discourse in the research and teaching community in relation to what constitutes sustainable 'teaching excellence' and the importance of centering oneself between the needs of the corporate university and the needs of students.

\section{References}

Altbach, P. G. (2007). The Internationalization of Higher Education: Motivations and Realities. Journal of Studies in International Education, 11(3/4), 290-305.

Ball, S. J. (2015). Education, governance and the tyranny of numbers. Journal of Education Policy, 30(3), 299-301.

Beauchamp, G., Clarke, L., Hulme, M., Jephcote, M., Kennedy, A., Magennis, G., . . Peiser, G. (2016). Teacher education in times of change. Bristol: Bristol University Press.

Berg, M., Seeber, B.K. (2016). The Slow Professor - Challenging the Culture of Speed in the Academy. Buffalo, London: University of Toronto Press.

Kreber, C. (2002). Teaching Excellence, Teaching Expertise, and the Scholarship of Teaching. Innovative Higher Education, 27(1), 5-23.

Lunenberg, M., Dengerink, J., Korthagen, F. (2014). The Professional Teacher Educator: Roles, Behaviour, and Professional Development of Teacher Educators. Rotterdame, The Netherlands: Sense Publishers.

Perrott, E. (1982). Effective Teaching: A Practical Guide to Improving Your Teaching. New York: Longman.

Ramsden, P. (1991). A Performance Indicator of Teaching Quality in Higher Education: the Course Experience Questionnaire Studies in Higher Education, 16(2), 129-150.

Steck, H. (2003). Corporatization of the University: Seeking Conceptual Clarity. The Annals of the American Academy of Political and Social Science, 585, 66-83. doi:www.jstor.org/stable/1049751 